\section{Resistant hypertension in elderly patient with nephropathy in primary and secondary care settings}

\author{
Valerio Massimo Magro, \\ Michele Caturano, ${ }^{1}$ Fulvio Cacciapuoti, ${ }^{2}$ \\ Diana Lama, ${ }^{1}$ Federico Cacciapuoti ${ }^{1}$ \\ ${ }^{1}$ Department of Internal Medicine and \\ Geriatrics, Second University of Naples; \\ ${ }^{2}$ Center of Cardiology and Internal \\ Medicine, Cardarelli Hospital, Naples, \\ Italy
}

\begin{abstract}
Resistant hypertension is defined as a blood pressure above therapeutic goals, despite the concurrent use of three or more antihypertensive drugs of different pharmacological classes, and all being administered according to an optimum dosage schedule. The prevalence of resistant hypertension in the older people has not yet been exactly quantified. The updated available estimates deriving from some clinical trials report a prevalence of approximately $20-30 \%$ of all hypertensive patients. Advanced age seems to be an important risk factor in resistant forms of high blood pressure. Therefore this clinical condition may potentially increase in the coming years. Chronic kidney disease is the most frequent comorbidity associated with resistant hypertension and often leads to poor prognosis. The article describes a case report of an older subject with such a clinical condition suggesting diagnostic and therapeutic plan based on a rational strategy to control hypertension and the most recent knowledge reported in the medical literature.
\end{abstract}

\section{Introduction}

Resistant hypertension is a clinical condition frequently leading to high-risk cardiovascular events, despite patients take at least three or more antihypertensive drugs (including a diuretic) and change their lifestyle (Figure 1). It refers to all clinical pictures in which, despite such interventions, blood pressure does not fall within target limits or four or more drugs at full dosage are required to control it. Chronic kidney disease (CKD) is the most frequent comorbidity associated with resistant hypertension and often leads to poor prognosis. ${ }^{1} \mathrm{~A}$ therapeutic approach tailored to the individual patients should preliminarily aim to identify modifiable factors, such as the principles of health education, including the recommendation to follow a healthy diet, the use of synergic drugs, a rational timing of administration to avoid side effects and a strict clinical follow up. We describe a case report in which we targeted such modifiable factors.

\section{Case Report}

The case refers to a 73-year-old man with high blood pressure, hypercholesterolemia, type 2 diabetes mellitus with macro- and micro-vascular complications (such as proliferative retinopathy, hypertensive and diabetic nephropathy, sensitive and motor symmetricdistal polyneuropathy), a history of ischemic heart disease with previous acute myocardial infarction treated with percutaneous coronary intervention and coronary artery stent insertion and peripheral arterial disease in chronic treatment since many years. In 2008 the patient underwent percutaneous transluminal angioplasty (PTA) and external left iliac artery and superficial left femoral artery stent placement; thrombectomy of right femoropopliteal artery and PTA with stent on right popliteal artery and external iliac artery placement. He also developed CKD, benign prostatic hyperplasia and had a recent acute attack of gout treated with colchicine ( $0.5 \mathrm{mg}$ daily). CKD has progressively worsened over the last two years and at the moment of the clinical visit was currently at the Kidney Disease Outcomes Quality Initiative (KDOQI) stage 4 (glomerular filtration rate $25 \mathrm{~mL} / \mathrm{min} / 1.73 \mathrm{~m}^{2}$ ). The current medications taken by the patient were bumetanide $2.5 \mathrm{mg}$ daily, moxonidine $0.4 \mathrm{mg}$ daily, barnidipine $20 \mathrm{mg}$ daily, terazosin $1 \mathrm{mg}$ daily, aspirin $100 \mathrm{mg}$ daily, clopidogrel $75 \mathrm{mg}$ daily, atorvastatin $80 \mathrm{mg}$ daily, pregabalin 300 $\mathrm{mg}$ daily, febuxostat $80 \mathrm{mg}$ daily, calcitriol 0.5 mcg daily, basal-bolus insulin therapy with lispro and glargine bedtime. Blood pressure was $160 / 70 \mathrm{mmHg}$ over the last two weeks with heart rate of $68 \mathrm{bpm}$ and a regular rhythmic activity of the heart.

\section{Results}

The patient was in fairly good general conditions. At the first visit blood test examination demonstrated fasting glucose $180 \mathrm{mg} / \mathrm{dL}$, blood count erythrocytes $4.14 \times 106 / \mathrm{mcL}$ with a normochromic and normocytic anemia (hemoglobin value $10 \mathrm{~g} / \mathrm{dL}$ ); serum iron level $60 \mathrm{mcg} / \mathrm{dL}$, serum creatinine $3 \mathrm{mg} / \mathrm{dL}$, serum urea 113 $\mathrm{mg} / \mathrm{dL}$, potassium $4.8 \mathrm{mE} / \mathrm{L}$, and serum plasma sodium, calcium and chloride were within the normal range. Total serum protein $6.5 \mathrm{~g} / \mathrm{dL}$, uric acid $9 \mathrm{mg} / \mathrm{dL}$, fibrinogen $600 \mathrm{mg} / \mathrm{dL}$, and serum
Correspondence: Valerio Massimo Magro, Department of Internal Medicine and Geriatrics, Second University of Naples, Piazza L. Miraglia 2, 80100 , Naples, Italy.

Tel: +39.3492224922 .

E-mail:valerio_magro@hotmail.com

Key words: Resistant hypertension; kidney failure; elderly patient; cardiovascular risk.

Contributors: VMM and MC, research leading and manuscript writing; FC1, DL, FC2, research conducting and manuscript editing. VMM, FCl and FC2, overall article design, data collection, manuscript revision and approval.

Conflict of interest: the authors declare no poten tial conflict of interest.

Received for publication: 1 May 2016.

Revision received: 9 October 2016.

Accepted for publication: 18 October 2016.

This work is licensed under a Creative Commons Attribution-NonCommercial 4.0 International License (CC BY-NC 4.0).

(C) Copyright V.M. Magro et al., 2016

Licensee PAGEPress, Italy

Geriatric Care 2016; 2:5968

doi:10.4081/gc.2016.5968

albumin $3.2 \mathrm{~g} / \mathrm{dL}$, low-density lipoprotein serum concentration $150 \mathrm{mg} / \mathrm{dL}$, high-density lipoprotein serum concentration $30 \mathrm{mg} / \mathrm{dL}$ and triglycerides $170 \mathrm{mg} / \mathrm{dL}$. Microalbuminuria of 295 $\mathrm{mg} / \mathrm{L}$. After a thorough examination of the case, our multi-disciplinary team decided to increase the dosage of terazosin to $2 \mathrm{mg}$ daily, which was then titrated up to $5 \mathrm{mg}$, and to leave the rest of the treatment plan unchanged, as no adverse events had occurred. In agreement with the patient no peritoneal dialysis was performed. After two months of follow-up, the patient reached the target blood pressure values. After clinical assessment and discussion with the patient's General Practitioner and the nephrologist, we agreed with the patient to continue the medical therapy and to consider the renal replacement therapy with hemodialysis in the near future. We also pay great attention to increase the patient's compliance to diet and medical therapy.

\section{Discussion}

The Seventh Report of the Joint National Committee on Prevention, Detection, Evaluation and Treatment of High Blood Pressure (JNC 7, 2003) ${ }^{2}$ defined a treatment goal of blood pressure values of less than $140 / 90 \mathrm{mmHg}$ for patients with hypertension 
and no other severe conditions. These guidelines include a separate recommendation referring to a target blood pressure of less than $130 / 80 \mathrm{~mm} \mathrm{Hg}$ for all patients with CKD, defined as reduced glomerular filtrate rate. ${ }^{3} \mathrm{~A}$ study by Sarafidis and collaborators showed that hypertension is highly prevalent in predialysis CKD patients with a high prevalence of hypertension (95\%) in the studied population. ${ }^{4}$ Some trials, such as ACCOMPLISH, VALUE, INCLUSIVE and others, showed that strategies based on the use of combination therapies could achieve very high rates of controlled-patients, despite some of them were difficult or seemingly resistant cases. ${ }^{5}$ In this case report, no optimal blood pressure values were obtained despite patient was administered drugs of different classes. Levels greater than $140 / 90 \mathrm{mmHg}$ were observed in spite of the concomitant use of a calcium channel blocker, a $\alpha$-lytic drug, a diuretic and an antiadrenergic agent.

The achievement of blood pressure control was an important factor to avoid an increase in the cardiovascular risk and a fast decline of the renal function. In our patient, diuresis was not particularly enhanced given the presence of several contraindications for diuretics, such as thiazide, which is potassium-sparing with an increased risk of hyperkalaemia. Thus, we used a low dose of bumetanide. The potassium serum level of the patient did not allow for the use of drugs with activity on the reninangiotensin system. The loop diuretics have the same adverse effects as thiazide diuretics (hyponatremia and electrolyte imbalance and hyperuricemia) and also increase urinary cal- cium excretion. A recent study was conducted to assess the effect of intensifying diuretic treatment with a loop diuretic (furosemide) or an aldosterone antagonist (spironolactone) on blood pressure control in resistant hypertension therapy. Spironolactone proved to be more effective than furosemide in controlling blood pressure in these patients. A positive additional effect was also observed on albuminuria, although serum potassium should be closely monitored, especially in diabetics like our patient with a high risk of hyperkalemia and variable rates of gynecomastia. ${ }^{6}$ Despite the heart rate was good, no $\beta$-blockers were administered due to the presence of the peripheral artery disease and to conflicting experts' opinions about the combination between beta-blockers and anti-adrenergic agents. Moxonidine is a centrally acting antiadrenergic drug indicated in hypertension resistant to other antihypertensive drugs: the dose with the above-mentiones glomerular filtration rate could not exceed $0.4 \mathrm{mg}$. Based on the promising results of the low-dose colchicine for secondary prevention of cardiovascular disease trial, ${ }^{7}$ colchicine was administered with caution to prevent vascular damage in the lower limbs at the level of metatarsophalangeal inflammation, considering some evidence of positive effects of this drug in cardiac patient. ${ }^{8}$ Soon after a sudden worsening of CKD, this drug was replaced with febuxostat, although its efficacy and safety have not yet been assessed conclusively in severe CKD patients (there was a significant hyperuricemia, independent risk factor of cardiovascular mortality). Dual antiplatelet therapy was

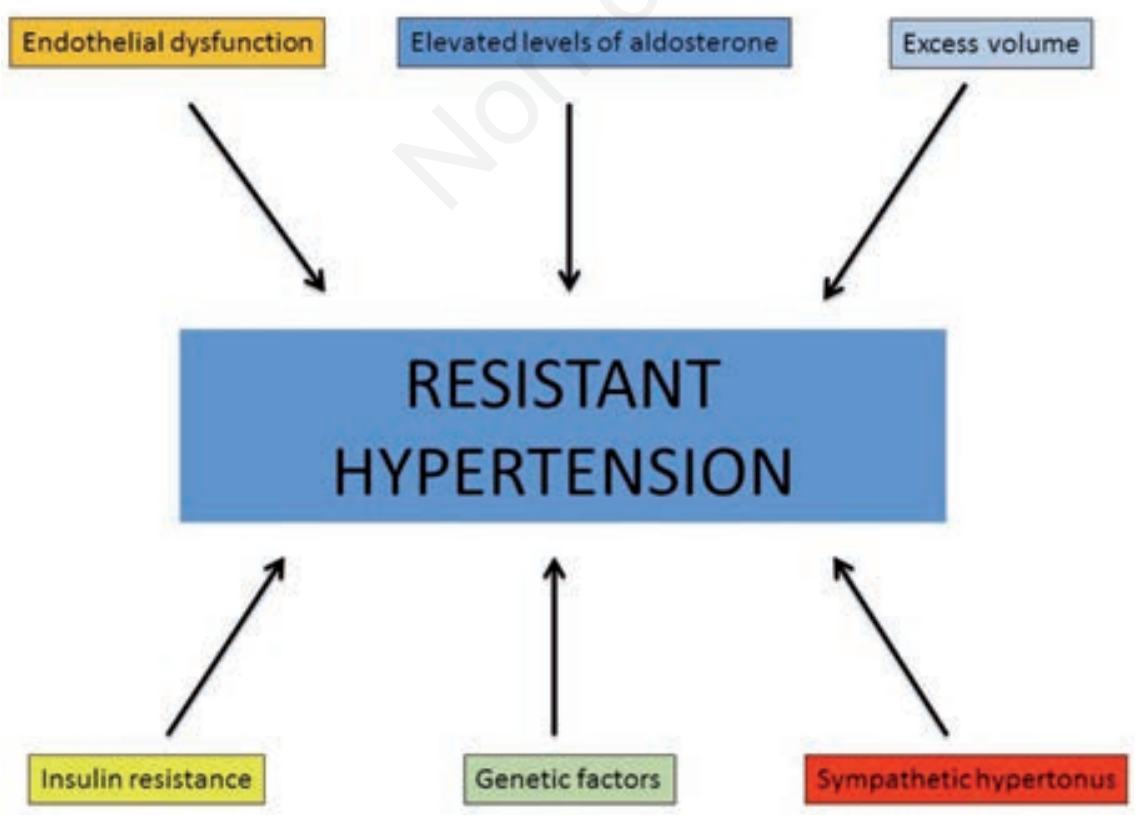

Figure 1. Main pathophysiological mechanisms of the resistant arterial hypertension. continued incessantly due to the nature of this major vascular disease with involvement of multiple arterial portions (not only the coronary system) and restenosis (with several risk factors of the patient, including diabetes, hypertension, dyslipidemia and the CKD). This was also useful to maintain the patency of vessels also in the upper limbs, considering the potential risk of an artero-venous fistula in the future. Thus, we decided to change the alphalytic drug dosage and maintained a single dose in the evening to avoid orthostatic hypotension, which in the treatment of blood hypertension occurs much more frequently in patients older than 65 and over (5.6\%), like our patient, than under 65 years (2.6\%). ${ }^{9}{ }^{10}$ Another promising treatment of resistant hypertension is shown by results of the SIMPLICITY-HTN-3 trial based on the execution of renal denervation. Beyond the operator dependence of the treatment (partial denervation could cause sensitization of the remaining nerves, inflammation of the nerves, or growth of new nerves, which could exacerbate the degree of hypertension), ${ }^{11}$ we also observed that the majority of enrolled patients in this trial were frankly obese, unlike our patient, with a mean body mass index in the renal denervation group $34.2 \pm 6.5 \mathrm{~kg} / \mathrm{m}^{2}$ (sympathetic nerve activity, including renal sympathetic nerve activity, is known to be elevated in human obesity) and a greater blood pressure reduction in patients with obstructive sleep apnea. Although this point of view was debated by other Authors, our opinion is that the clinical implications of the difference in sympathetic nerve firing between obese and lean hypertensive patients are still unknown. Therefore, despite the trial was very promising, we did not feel this patient to be suitable for this procedure and preferred to wait for additional post-hoc analysis of SYMPLICITY HTN-3 data and clinical implications in future studies. ${ }^{12,13}$

\section{Conclusions}

According to latest data, such as those of the National Health and Nutrition Examination Survey (NHANES) ${ }^{14}$ and the Framingham study, ${ }^{15,16} 32 \%$ of Italian subjects with high blood pressure are compliant with therapy, however only $9 \%$ of them have a blood pressure level below 140/90 mmHg. According to the European Society of Cardiology-European Society of Hypertension (ESC-ESH), the presence of CKD and heart disease in patients with grade two hypertension is an additional risk factor that significantly increases the risk of cardiovascular events in 10 years. ${ }^{17,18}$ Evidence show that high blood pressure can be treated in many difficult cases by a clinical and therapeutic plan based on a rational strategy to con- 
trol hypertension and the most recent knowledge reported in the medical literature, ${ }^{19}$ which is set to provide new therapeutic options for the optimization of the drug therapy combination.

\section{References}

1. Rossignol P, Massy ZA, Azizi M, et al. The double challenge of resistant hypertension and chronic kidney disease. Lancet 2015; 386:1588-98.

2. Himmelmann A, Kjeldsen SE, Hedner T. Recent hypertension guidelines: JNC-7 and 2003 ESH/ESC. Blood Press 2003;12: 196-7.

3. Whitworth JA. World Health Organization ISoHWG. 2003 World Health Organization (WHO)/International Society of Hypertension (ISH) statement on management of hypertension. J Hypertens 2003;21:1983-92.

4. Sarafidis PA, Sharpe CC, Wood E, et al. Prevalence, patterns of treatment, and control of hypertension in predialysis patients with chronic kidney disease. Nephron Clin Pract 2012;120:c147-55.

5. Taddei S. Combination therapy in hypertension: what are the best options according to clinical pharmacology principles and controlled clinical trial evidence? Am J Cardiovasc Drugs 2015;15:185-94.

6. Verdalles U, García de Vinuesa $\mathrm{S}$, Goicoechea M, et al. Management of resistant hypertension: aldosterone antag- onists or intensification of diuretic therapy? Nephrology (Carlton) 2015;20:567-71.

7. Stefan MN, John WE, Charley AB, et al. Low-dose colchicine for secondary prevention of cardiovascular disease. J Am Coll Cardiol 2013;61:404-10.

8. Tong DC, Wilson AM, Layland J. Colchicine in cardiovascular disease: an ancient drug with modern tricks. Heart 2016 [Epub ahead of print].

9. Torrinomedica srl. Moxonidina eg compresse rivestite con film. Riassunto delle caratteristiche del prodotto. Available from: http://www.torrinomedica.it/farmaci/schedetecniche/Moxonidina_Eg_Compr esse_Rivestite_Con_Film.asp\#axzz47Kex d3WZ

10. The Electronic Medicines Compendium (eMC). Terazosin $5 \mathrm{mg}$ tablets. Available from: https://www.medicines.org.uk/emc/ medicine/25842

11. Burchell AE, Chan K, Ratcliffe LE, et al. Controversies Surrounding Renal Denervation: Lessons Learned From RealWorld Experience in Two United Kingdom Centers. J Clin Hypertens (Greenwich) 2016;18:585-92.

12. Bakris GL, Bhatt DL. Reply: A mechanistic explanation for the minimal impact of renal denervation on 24-h ambulatory blood pressure in SIMPLICITY HTN-3. J Am Coll Cardiol 2015;65:959-60.

13. Kario K, Bhatt DL, Kandzari DE, et al. Impact of renal denervation on patients with obstructive sleep apnea and resistant hypertension. Insights from the SYMPLICITY HTN-3 Trial. Circ J 2016;80:1404-12.
14. Wolf-Maier K, Cooper RS, Kramer H, et al. Hypertension treatment and control in five European countries, Canada, and the United States. Hypertension 2004;43:10-7.

15. Sciarretta S, Valenti V, Tocci G, et al. Association of renal damage with cardiovascular diseases is independent of individual cardiovascular risk profile in hypertension: data from the Italy - Developing Education and awareness on MicroAlbuminuria in patients with hypertensive Disease study. J Hypertens 2010;28:251-8.

16. Volpe M, Rosei EA, Ambrosioni E, et al. Reduction in estimated stroke risk associated with practice-based stroke-risk assessment and awareness in a large, representative population of hypertensive patients: results from the ForLife study in Italy. J Hypertens 2007;25:2390-7.

17. Liakos CI, Grassos CA, Babalis DK. 2013 $\mathrm{ESH} / \mathrm{ESC}$ guidelines for the management of arterial hypertension: what has changed in daily clinical practice? High Blood Press Cardiovasc Prev 2015;22:43-53.

18. Galletti F, Barbato A; Minisal-Gircsi Study Group. Prevalence and determinants of resistant hypertension in a sample of patients followed in Italian hypertension centers: results from the MINISAL-SIIA study program. J Hum Hypertens 2016 [Epub ahead of print].

19. Drexler YR, Bomback AS. Definition, identification and treatment of resistant hypertension in chronic kidney disease patients. Nephrol Dial Transplant 2014;29: 1327-35. 